\title{
Czynniki prognostyczne u chorych z przerzutami raka piersi do mózgu
}

\author{
Tomasz Walasek¹, Beata Sas-Korczyńska², Paweł Blecharz ${ }^{3}$, \\ Jerzy W. Mituś ${ }^{4}$, Marian Reinfuss ${ }^{1}$
}

Wystąpienie przerzutów do mózgu u chorych na raka piersi (BMBC - brain metastases from breast cancer) związane jest z wyraźnie niekorzystnym rokowaniem. Mediana przeżycia u takich chorych waha się od 2 do 16 miesięcy, w zależności od wielu czynników prognostycznych oraz związanych z nimi możliwości leczenia. W piśmiennictwie prezentowane są czynniki prognostyczne ujawniające się w badaniach jedno- lub wieloośrodkowych, głównie, choć nie jedynie, w analizach wieloczynnikowych, oraz czynniki uwzględnione windeksach prognostycznych, opracowanych dla chorych z przerzutami do mózgu z różnych nowotworów lub - w szczególności — dla chorych z BMBC. Zebrane i zweryfikowane dane piśmiennictwa pozwalają uznać, że na chwilę obecną podstawowymi, powszechnie uznanymi Czynnikami prognostycznymi u chorych z BMBC są: stan sprawności chorych oraz stan procesu nowotworowego poza mózgiem w momencie ujawnienia się przerzutów do mózgu (BM — brain metastases). Stan sprawności chorych oceniany jest prawie wyłącznie skalą Karnofsky'ego, natomiast stan procesu nowotworowego jest różnie definiowany: czynny vs nieobecny, kontrolowany vs niekontrolowany, obecność przerzutów odległych poza mózgiem vs brak tych przerzutów itp. Niestety, stwarza to możliwość różnych interpretacji. Potencjalnymi czynnikami prognostycznymi prezentowanymi przez wielu autorów, ale nieuznawanymi powszechnie, są: wiek chorych, podtyp molekularny raka piersi oraz liczba BM. Wyniki przeprowadzonych analiz oceniających wartości poszczególnych indeksów prognostycznych wskazują, że pomimo niewątpliwych ich zalet, w praktyce klinicznej winny być stosowane z rozwagą u chorych z BMBC.

\section{Prognostic factors of brain metastases in patients with breast cancer}

The development of brain metastases from breast cancer (BMBC) relates to poor prognosis. The median survival rate averages from 2 to 16 months and depends on various prognostic factors and therapeutic possibilities. There are some prognostic factors which were found in trials as a results of multivariate analyses and factors from prognostic scores in patients with brain metastases. According to the literature the important prognostic factors are performance status and status of the disease outside the brain. Performance status usually is evaluated according to the Karnofsky scale. Whereas the disease status is estimated variously as: presence versus no disease, controlled or uncontrolled disease, presence or not of distant metastases outside the brain. Many authors revealed that age, molecular type of breast cancer and number of brain metastases are potential prognostic factors. Published results of analyses showed that the role of some prognostic factors is limited in patients with BMBC.

Słowa kluczowe: rak piersi, przerzuty do mózgu, czynniki prognostyczne

Key words: breast cancer, brain metastases, prognostic factors

\author{
${ }^{1}$ Zakład Radioterapii \\ ${ }^{2}$ Oddział Nowotworów Piersi i Klatki Piersiowej, Klinika Onkologii \\ ${ }^{3}$ Klinika Ginekologii Onkologicznej \\ ${ }^{4}$ Klinika Chirurgii Onkologicznej \\ Centrum Onkologii — Instytut im. Marii Skłodowskiej-Curie, Oddział w Krakowie
}




\section{Wstęp}

Rak piersi (BC - breast cancer) jest drugą po raku płuca (40-50\%) najczęstszą przyczyną przerzutów do mózgu (BMBC - brain metastases from breast cancer) (15-25\%) [1-6]. Przyczynami systematycznego wzrostu częstości rozpoznawania BMBC są:

- ogólny wzrost zachorowalności na nowotwory, związany ze starzeniem się populacji,

- wydłużenie czasu przeżycia chorych na BC, związanego z leczeniem adiuwantowym,

- lepsza skuteczność leczenia uogólnionego BC,

- oraz postęp w zakresie technik obrazowania mózgu [1, 3, 5, 7-10].

BMBC pojawiają się zazwyczaj w późnych, zaawansowanych stadiach procesu nowotworowego, najczęściej po uprzednim wystąpieniu przerzutów odległych poza mózgiem [2, 4, 5, 11]. Mediana czasu, jaki upływa pomię$\mathrm{dzy}$ rozpoznaniem $\mathrm{BC}$, a wystąpieniem $\mathrm{BMBC}$, jest różna dla różnych podtypów molekularnych $B C$ i wynosi: 28,36 , 47 i 54 miesiące odpowiednio dla BC potrójnie ujemnego (TN - triple negative), z nadekspresją HER2, luminalnego B i luminalnego $A[1,12,13]$.

W leczeniu BMBC stosuje się chirurgię, stereotaktyczną radiochirurgię (SRS - stereotactic radiosurgery), napromienianie całego mózgowia (WBRT-whole brain radiotherapy), leczenie systemowe oraz kojarzenie tych metod [5, 7, 14-26]. Preferowane jest leczenie lokalne (chirurgia, SRS) [5, 7, 9, 16, 22-25] i regionalne (WBRT) [5, 7, 15, 18, 20, 24-26] oraz ewentualne kojarzenie chirurgii i radioterapii. Coraz bardziej istotną rolę odgrywać zaczyna leczenie systemowe, a szczególnie leczenie ukierunkowane molekularnie [5, 7, $14,17-20,22,23]$
Mediana przeżycia chorych z BMBC nieleczonych wynosi ok. 1 miesiąca, leczonych wyłącznie kortykosterydami - 2 miesiące, poddanych WBRT - 3-6 miesięcy, a w bardzo wyselekcjonowanych grupach chorych, z 1-3 BM, leczonych chirurgicznie lub SRS z ewentualnym następowym WBRT - 10-12 miesięcy [1, 27]. W sumie wystąpienie BMBC związane jest z wyraźnie niekorzystnym rokowaniem. Mediana czasu przeżycia u takich chorych waha się od 2 do 16 miesięcy, w zależności od wielu czynników prognostycznych oraz związanych z nimi możliwości leczenia [1, 3-5, 7, 12, 15, 26-30].

\section{Potencjalne czynniki prognostyczne u chorych z BMBC}

W piśmiennictwie istnieje duża liczba publikacji poświęconych badaniom nad identyfikacją czynników prognostycznych u chorych z BMBC $[1,3-5,7,9,12,14,15$, 20, 22-25, 31-69]. Najczęściej prezentowane są czynniki prognostyczne w odniesieniu do przeżycia całkowitego (OS - overall survival) liczonego od momentu ujawnienia BM, w oparciu o analizy jedno- i wieloczynnikowe, co zostało zestawione $w$ tabeli I.

Jak wynika z tabeli I oraz danych piśmiennictwa, głównym czynnikiem prognostycznym u chorych z BMBC jest stan sprawności chorej oceniany według skali Karnofsky'ego (KPS - Karnofsky Performance Scale) [1, 15, 19, 22, 24, 25, 36, 38, 40, 46-48, 53-55, 58-63, 65, 69, 70]. Zdecydowana większość autorów, za wartość KPS różnicującą rokowniCzo, przyjmuje 70; nieliczni sugerują 80 [24] lub 60 [65], a w niektórych indeksach prognostycznych wartość KPS różnicowana jest np. $\leq 50$ vs $60-70$ vs $80-100$ [36], $<70$ vs $70-80$ vs $90-100[70], \leq 60$ vs $70-90$ vs $100[60], \leq 50$ vs 60 vs $70-80$ vs $90-100[54]$.

Tabela I. Potencjalne czynniki prognostyczne najczęściej prezentowane w piśmiennictwie u chorych z BMBC

\begin{tabular}{|c|c|c|c|c|c|}
\hline \multirow{2}{*}{$\begin{array}{l}\text { Autor, pozycja piśmiennictwa, } \\
\text { rok publikacji }\end{array}$} & \multicolumn{5}{|c|}{ Czynniki prognostyczne } \\
\hline & Wiek & KPS & $\begin{array}{c}\text { Stan procesu nowotworowego } \\
\text { poza mózgiem }\end{array}$ & Podtyp molekularny BC & Liczba BM \\
\hline Kased i wsp. [48], 2009 & & + & + & + & \\
\hline Matsunaga i wsp. [24], 2010 & + & + & + & + & + \\
\hline Aoyama [15], 2011 & & + & + & & + \\
\hline Gachet i wsp. [1], 2011 & + & + & + & + & \\
\hline Kondziołka i wsp. [25], 2011 & & + & & + & + \\
\hline Xu i wsp. [40], 2012 & + & + & + & + & + \\
\hline Vern-Gross i wsp. [53], 2012 & & + & + & + & \\
\hline Kaplan i wsp. [22], 2013 & & + & + & & \\
\hline Gerdan i wsp. [38], 2013 & & + & + & & \\
\hline Minisini i wsp. [12], 2013 & & & + & + & + \\
\hline Tabouret i wsp. [65], 2014 & & + & + & & \\
\hline
\end{tabular}

BMBC — brain metastases from breast cancer (przerzuty do mózgu); KPS — Karnofsky Performance Status; BC — breast cancer (rak piersi); BM — brain metastases (przerzuty do mózgu) 
Kolejnymi, często prezentowanymi w piśmiennictwie czynnikami prognostycznymi u chorych z BMBC, są: stan procesu nowotworowego poza mózgiem, podtyp molekularny BC, liczba BM i rzadziej - wiek chorych.

Stan procesu nowotworowego poza mózgiem jest różnie definiowany, między innymi: kontrolowany vs niekontrolowany $[9,12,19,20,25,60]$, czynny vs nieobecny $[60,65]$, wyleczony lokoregionalnie vs niewyleczony [30, 48], z obecnością przerzutów odległych poza mózgiem vs z brakiem tych przerzutów [24, 30, 46, 70, 71]. Czynnikiem rokowniczym może być tutaj lokalizacja przerzutów odległych (np. kości vs narządy miąższowe), a nawet liczba narządów poza mózgiem, w których stwierdza się obecność przerzutów odległych $[5,19,38,59,60]$.Tak więc możliwości interpretacji tego niewątpliwie ważnego czynnika prognostycznego jest wiele.

Rzeczywista wartość prognostyczna podtypu molekularnego $B C$ u chorych z BMBC jest przedmiotem kontrowersji. Nie ulega wątpliwości, że chore z potrójnie ujemnym BC oraz z nadeskpresją HER2 mają wyraźnie wyższe ryzyko wystąpienia $\mathrm{BM}$ w porównaniu z pozostałymi podtypami molekularnymi $B C[17,18,20,23$, $32,60,66,72,73]$. Z drugiej strony zastosowanie leczenia trastuzumabem po wystąpieniu BM istotnie wpływa na przedłużenie życia chorych na BC z nadekspresją HER2. W tym przypadku mediana czasu przeżycia jest obecnie najdłuższa we wszystkich podtypach molekularnych $B C[1,5,7,17,19$, 23, 31, 60, 72-75]. Istnieje wiele doniesień piśmiennictwa wskazujących na różnice w przeżyciach pomiędzy poszczególnymi podtypami molekularnymi BC z BM. Największa wartość mediany przeżycia całkowitego obserwowana jest, jak zaznaczono to powyżej, u chorych na BC z nadekspresją HER2, oczywiście pod warunkiem stosowania leczenia anty-HER2, a najkrótsza - u chorych z podtypem TN [5, 12, 41, 42, 49-53, 60], jednak bardzo niewielu autorów potwierdza prognostyczne znaczenie podtypu molekularnego BC w analizach wieloczynnikowych [24, 25, 53]. W ogromnej większości analiz cecha ta nie jest czynnikiem prognostycznym, a stwierdzone różnice są albo w ogóle nieznamienne statystycznie [3, 4, 14, 41, 60], albo podtyp molekularny ujawnia się jako potencjalny czynnik prognostyczny jedynie w analizach jednoczynnikowych [4, 19, 34, 60] lub jako jeden z kilku czynników w tzw. indeksach prognostycznych [54, 58, 60, 61, 64, 65, 69]. Należy zaznaczyć, że w u chorych na BC nadekspresja HER2 jest niekorzystnym czynnikiem prognostycznym (skrócenie naturalnego przebiegu), a równocześnie jest pozytywnym czynnikiem predykcyjnym (wydłużenie czasu przeżycia w przypadku zastosowania leczenia celowanego). Jeżeli nawet uznać, że w grupie chorych z BMBC pacjentki z nadespresją HER2 mają lepsze rokowanie, niż chore na inne podtypy molekularne BC, to dzieje się to pod warunkiem aplikacji specyficznego leczenia, które obecnie jest standardem postępowania. Stąd też chore, które nie otrzymały leczenia anty- HER2, nie powinny być włączane do badań oceniających czynniki prognostyczne u chorych z BMBC [65].

Kontrowersje budzi również prognostyczne znaczenie liczby BM u chorych z BMBC [4, 22, 24, 25, 30, 36, 56, 58-61, 63-65, 68-71, 75, 76]. Część autorów wykazuje prognostyczne znaczenie tego czynnika w analizach jedno- lub wieloczynnikowych $[4,5,12,15,25,40,60,62,63,69]$, a wielu nie wykazuje zupełnie [14, 22, 24, 37-39, 43-45, 48, 53, 65]. Należy podkreślić, że liczba BM odgrywa istotną rolę przy wyborze leczenia lokalnego (chirurgia, SRS) lub lokoregionalnego (WBRT).

W piśmiennictwie istnieje pewna liczba doniesień sugerujących potencjalną wartość prognostyczną wieku chorych z BMBC, opartych na analizach jedno-i wieloczynnikowych [1, 2, 4, 40, 58-60, 69]. Za wartość różnicującą rokowniczo najczęściej przyjmuje się wiek 60 lub 65 lat [30, 58, 69], rzadziej 50 lat [36, 70], jednak obserwacje wielu autorów nie potwierdzają prognostycznego znaczenia wieku u chorych z BMBC $[1,22,25,40,58,59,63,64,68,77]$.

W nielicznych doniesieniach w piśmiennictwie pojawia się wiele innych potencjalnych czynników prognostycznych, takich jak np. czas, jaki upływa od diagnozy BC do pojawienia się BM [25, 55, 56, 65], liczba narządów poza mózgiem z przerzutami odległymi [38], obecność przerzutów do wątroby $[5,19,60]$, obecność objawów neurologicznych [24], lokalizacja BM w głębokich strukturach mózgu [25], martwica w BMBC [40], wymiar największego BM lub suma objętości przerzutów [24, 25, 40, 55], limfopenia [7, 61, 68], poziom dehydrogenazy mleczanowej (LDH) i albumin w surowicy krwi [67] itd.

\section{Czynniki prognostyczne uwzględnione w indeksach prognostycznych opracowanych dla chorych z przerzutami do mózgu z różnych nowotworów}

Celem badań, zasadniczo retrospektywnych, prowadzonych nad opracowaniem indeksów prognostycznych (PS - prognostic scores) dla chorych z BM było: zdefiniowanie grup chorych o różnym rokowaniu i stworzenie możliwości przewidywania prawdopodobnego czasu przeżycia konkretnego chorego, uściślenie wskazań do stosowania dostępnych metod leczenia, poprawa stratyfikacji i interpretacji kontrolowanych badań klinicznych, porównanie homogenności grup chorych ocenianych retrospektywnie $[58,59]$. Początkowo opracowane i stosowane w praktyce klinicznej PS dotyczyły wszystkich chorych z BM, niezależnie od typu nowotworu pierwotnego, obecnie wprowadzane są PS dostosowane do konkretnych nowotworów, będących główną przyczyną BM, a więc raka płuca, raka piersi i czerniaka [78].

Indeksy prognostyczne opracowane dla chorych z BM z różnych nowotworów pierwotnych (głównie tj. 53-77\% dla 
Tabela II. Czynniki prognostyczne uwzględnione w indeksach prognostycznych dla chorych z BM z różnych nowotworów

\begin{tabular}{|c|c|}
\hline $\begin{array}{l}\text { Indeks prognostyczny, } \\
\text { pozycja piśmiennictwa, } \\
\text { rok publikacji }\end{array}$ & Czynniki prognostyczne \\
\hline RPA-RTOG [30], 1997 & $\begin{array}{l}\text { wiek: }<65 \text { vs } \geq 65 \\
\text { KPS: }<70 \text { vs } \geq 70 \\
\text { obecność przerzutów poza mózgiem: tak vs nie } \\
\text { kontrola choroby podstawowej: tak vs nie }\end{array}$ \\
\hline Rotterdam [56], 1999 & $\begin{array}{l}\text { stan sprawności wg ECOG: 0-1 vs 2-3 } \\
\text { przerzuty pozamózgowe: brak aktywności lub aktywność nieznaczna vs znaczna aktywność } \\
\text { skuteczność indukcyjnej kortykosterydoterapii: dobra vs średnia vs słaba }\end{array}$ \\
\hline SIR [36], 2000 & $\begin{array}{l}\text { wiek: }<50 \text { vs } 51-59 \text { vs } \geq 60 \\
\text { KPS: } 80-100 \text { vs } 60-70 \text { vs } \leq 50 \\
\text { stan choroby poza mózgiem - całkowita remisja lub izolowane BM vs częściowa remisja lub stabilizacja vs progresja } \\
\text { liczba BM: } 1 \text { vs } 2 \text { vs } \geq 3 \\
\text { objętość największego BM: } 5 \mathrm{~cm}^{3} \text { vs } 5-13 \mathrm{~cm}^{3} \text { vs }>13 \mathrm{~cm}^{3}\end{array}$ \\
\hline BSBM [77], 2004 & $\begin{array}{l}\text { KPS: } 80-100 \text { vs } \leq 70 \\
\text { przerzuty poza mózgiem: nie vs tak } \\
\text { kontrola choroby podstawowej: tak vs nie }\end{array}$ \\
\hline GPA [70], 2008 & $\begin{array}{l}\text { wiek: }<50 \text { vs } 50-59 \text { vs } \geq 60 \\
\text { KPS: } 90-100 \text { vs } 70-80 \text { vs }<70 \\
\text { przerzuty poza mózgiem: tak vs nie } \\
\text { liczba BM: } 1 \text { vs } 2-3 \text { vs }>3\end{array}$ \\
\hline Rades i wsp. [71], 2008 & $\begin{array}{l}\text { wiek: }<60 \text { vs } \geq 60 \\
\text { KPS: }<70 \text { vs } \geq 70 \\
\text { przerzuty poza mózgiem: tak vs nie } \\
\text { czas wolny od rozpoznania nowotworu do wystąpienia BM: }<8 \text { miesięcy vs } \geq 8 \text { miesięcy }\end{array}$ \\
\hline
\end{tabular}

RPA-RTOG — Recursive Partioning Analysis-Radiation Therapy Oncology Group; SIR — Score Index for Radiosurgery; BSBM — Basic Score for Brain Metastases; GPA — Graded Prognostic Assessment; KPS — Karnofsky Performance Status; BM — brain metastases

niedrobnokomórkowego raka płuca) i uwzględnione w nich czynniki prognostyczne zestawiono w tabeli II.

We wszystkich PS, zaprezentowanych w tabeli II, czynnikiem prognostycznym był stan sprawności chorych (KPS, ECOG) oraz obecność lub brak przerzutów pozamózgowych lub stan kontroli choroby podstawowej. W 4 z 6 PS czynnikiem prognostycznym był wiek, w 2 - liczba BM (dla chorych poddanych neurochirurgii - SIR i GPA).

\section{Czynniki prognostyczne uwzględnione w indeksach prognostycznych opracowanych dla chorych z BMBC}

Indeksy prognostyczne opracowane dla chorych z BMBC i uwzględnione w nich czynniki prognostyczne przedstawia tabela III.

Spośród 8 PS, przedstawionych w tabeli III, w 7 czynnikiem prognostycznym był stan sprawności chorego oceniany według skali Karnofsky'ego [58, 60, 61, 63, 64, 68, 69]. Kolejnymi, najczęściej uwzględnianymi czynnikami, były:

- obecność przerzutów poza mózgiem [63], kontrola choroby podstawowej $[60,69]$ albo liczba narządów poza mózgiem z obecnością przerzutów $[6,69]$,

- podtyp molekularny BC $[58,61,64,69]$,

- liczba BM $[60,63,69]$,

- wiek chorych $[58,61,69]$.

\section{Ocena wartości indeksów prognostycznych u chorych z BMBC}

W 2013 roku Braccini i wsp., w oparciu o analizę grupy 250 chorych z BMBC, porównali 7 PS, w tym 3 (RPA-RTOG, GPA i BSBM) dla różnych nowotworów, a 4 (breast GPA - Sperduto i wsp., breast - RPA - Niwińska i Murawska, Le Scodan i wsp. - P1PS) specyficzne dla BMBC. Przeprowadzone badania wykazały, że wszystkie porównywane PS, ze statystyczną znamiennością, różnicowały medianę przeżyć całkowitych (MOS - median overall survival) w zgodności z kategoriami przyjętymi dla danego PS. W analizie wielocechowej, RPA, GPA oraz Le Scodan i wsp. okazały się najlepszymi niezależnymi PS dla MSO. Oceniając PS, Le Scodan i wsp. podkreślają, że jego zaletą jest podkreślenie prognostycznego znaczenia podtypu molekularnego BC i parametrów krwi (limfopenia). Istotnie słabą stroną jest tutaj rozdział pomiędzy leczeniem trastuzumabem chorych z nadekspresją HER2 i chorych z TN BC [61]; Sperduto i wsp. oraz Niwińska i Murawska różnicują 4 podtypy molekularne $B C$ (luminalny $A$, luminalny $B, z$ nadekspresją HER2 i bazalny). W obu tych badaniach odpowiednio $77 \%$ i $50 \%$ chorych z nadekspresją HER2 otrzymało leczenie antyHER-2 [54,60]. W opinii autorów wadą GPA PS jest fakt, iż w klasie 3,5-4, najlepiej rokującej, było jedynie $2,8 \%$ chorych; jest to więc rzadka sytuacja w praktyce klinicznej, co ogranicza wartość 
Tabela III. Czynniki prognostyczne uwzględnione w indeksach prognostycznych dla chorych z przerzutami raka piersi do mózgu

\begin{tabular}{|c|c|}
\hline $\begin{array}{l}\text { Indeks prognostyczny, pozycja } \\
\text { piśmiennictwa, rok publikacji }\end{array}$ & Czynniki prognostyczne \\
\hline Claude [68], 2005 & $\begin{array}{l}\text { KPS: }<70 \text { vs } \geq 70 \\
\text { limfopenia }-\left(\leq 0,7 \times 10^{9}\right) \text { limfocytów }\end{array}$ \\
\hline Park i wsp. [64], 2009 & $\begin{array}{l}\text { KPS: } \leq 70 \text { vs }>70 \\
\text { nadekspresja HER2: tak vs nie } \\
\text { leczenie systemowe: tak vs nie }\end{array}$ \\
\hline Nieder i wsp. [63], 2009 & $\begin{array}{l}\text { KPS: }<70 \text { vs } \geq 70 \\
\text { przerzuty poza mózgiem: tak vs nie } \\
\text { liczba BM: } 1 \text { vs }>1 \\
\text { ID }<38 \text { miesięcy vs } \geq 38 \text { miesięcy }\end{array}$ \\
\hline Sperduto i wsp. [58], 2012 & $\begin{array}{l}\text { KPS: } \leq 50 \text { vs } 60 \text { vs } 70-80 \text { vs } 90-100 \\
\text { podtyp molekularny BC: bazalny vs luminalny A vs nadekspresja HER2 vs luminalny B } \\
\text { wiek: } \geq 60 \text { vs }<60\end{array}$ \\
\hline Niwińska i Murawska [60], 2012 & $\begin{array}{l}\text { KPS: } 100 \text { vs } 90-70 \text { vs } \leq 60 \\
\text { liczba BM: } 1-2 \text { vs }>2 \\
\text { stan choroby poza mózgiem: nieobecna lub kontrolowana vs niekontrolowana }\end{array}$ \\
\hline Le Scodan i wsp. [61], 2012 & $\begin{array}{l}\text { KPS: }<70 \text { vs } \geq 70 \\
\text { wiek: }<50 \text { vs } \geq 50 \\
\text { nadekspresja HER2(+) leczone transtuzumabem vs TN } \\
\text { limfopenia }\left(<0,7 \times 10^{9} / \mathrm{L}\right): \leq 700 \text { vs }>700\end{array}$ \\
\hline Antoni i wsp. [69], 2012 & $\begin{array}{l}\text { wiek: } \leq 50 \text { vs } 60 \text { vs } 70-80 \text { vs } 90-100 \\
\text { KPS: }<70 \text { vs } 70-80 \text { vs } 90-100 \\
\text { podtyp molekularny: bazalny vs inne } \\
\text { liczba BM: } 1-3 \text { vs }>3 \\
\text { liczba narządów z przerzutami poza mózgiem: } \geq 2 \text { vs } 1 \\
\text { kontrola choroby poza mózgiem: tak vs nie }\end{array}$ \\
\hline P1PS (phase 1 prognostic score) [67], 2010 & $\begin{array}{l}\text { liczba narządów z przerzutami poza mózgiem: } 0-2 \text { vs }>2 \\
\text { poziom LDH: norma vs powyżej normy } \\
\text { stężenie albumin }(\mathrm{g} / \mathrm{L}): \geq 35 \text { vs }<35\end{array}$ \\
\hline
\end{tabular}

KPS — Karnofsky Performance Status; BM — brain metastases; BC — breast cancer; TN — triple negative; LDH — dehydrogenaza mleczanowa

tego PS dla decyzji terapeutycznych. RPA PS bardzo dobrze prognozuje medianę przeżycia: w klasie I - $85 \%$ chorych przeżywa powyżej 12 miesięcy, a $62 \%$ w klasie III — przeżywa mniej niż 3 miesiące; żaden chory w klasie I nie żył krócej niż 3 miesiące i tylko 3\% chorych w klasie III żyło powyżej 12 miesięcy; w konkluzji Braccini i wsp. sugerują, że RPA wydaje się być najbardziej użytecznym PS u chorych $z$ BMBC [66].

W 2014 roku Tabouret i wsp., w oparciu o analizę grupy 152 chorych, przedstawili swoją ocenę 6 PS dla chorych z BMBC (Sperduto i wsp., Niwińska i Murawska, Park i wsp., Nieder i wsp., Le Scodan i wsp., Claude i wsp.) [65]. Mediana czasu przeżycia MOS w badanej grupie chorych od diagnozy BC do wykrycia BM wyniosła: w podtypie luminalnym $A-65,8$ miesiąca, luminalnym $B-41,3$ miesiąca, z nadekspresją HER2 - 29,2 miesiąca i w przypadku TN - 30,5 miesiąca. U 28\% chorych BM były pierwszymi ogniskami przerzutów odległych (u $37 \%$ chorych z TN i u $22 \%$ chorych z nadekspresją HER2). U 27\% chorych KPS był niższy od 70\%. Zdecydowana większość chorych otrzymała radioterapię lub - dodatkowo - kojarzenie napromieniania lub SRS z leczeniem systemowym. W grupie chorych z nadekspresją HER2 60\% pacjentek otrzymało leczenie anty-HER2 (27 chorych - trastuzumab, 7 chorych - la- patinib). MOS obliczonego od stwierdzenia BM wyniosła 14 miesięcy, przeżycie 1- i 2-letnie odpowiednio 53\% i 25\%. Wartości MOS w poszczególnych podtypach molekularnych przedstawiały się następująco:TN — 15,1 miesiąca, luminalny A - 12,3 miesiąca, z nadekspresją HER2 - 20,2 miesiąca i luminalny B - 20,5 miesiąca. W analizie wielocechowej niezależnymi, korzystnymi czynnikami prognostycznymi były: KPS > 60, brak choroby poza mózgiem, czas pomiędzy diagnozą BC i diagnozą BM > 40 miesięcy; zastosowanie leczenia systemowego, skojarzone leczenie miejscowe z SRS lub chirurgia. Liczba BM i wiek nie miały znaczenia prognostycznego.

Badaną grupę chorych sklasyfikowano wg wszystkich 6 porównywanych PS. Autorzy podkreślają, że niektóre klasy w PS były źle reprezentowane, np. w PS u Parka i wsp. były tylko 2 chore w klasie 4, a w PS Niwińska i Murawska - tylko 1 chora w klasie 1. Mimo to przeprowadzone badania wykazały, że wszystkie 6 porównywanych PS, ze statystyczną znamiennością, różnicowały medianę przeżyć całkowitych (MOS) w zgodności z kategoriami przyjętymi dla danego PS, natomiast ich zdolność dyskryminacyjna i pozytywna lub negatywna wartość predykcyjna były nieco różne.

Le Scodan i wsp. wyróżnili 3 klasy prognostyczne z MOS - 19,5, 12,5 i 3,5 miesiąca, odpowiednio dla klasy I, II i III. 
Główną słabością tego PS jest fakt zakwalifikowania chorych z podtypem TN do klasy III, bez względu na inne czynniki prognostyczne; Tabouret i wsp. podkreślają, że w ich analizie chore z TN miały MOS 15 miesięcy; samo rozpoznanie TN jest prawdopodobnie niewystarczające dla przewidywania szczególnie złego rokowania u chorych z BMBC.

Claude i wsp. w swoim PS oparli się na 2 potencjalnych czynnikach prognostycznych KPS i limfopenii i wyróżnili dwie grupy chorych: o złym rokowaniu (MOS - 3,2 miesiąca) i dobrym rokowaniu (MOS - 15,7 miesiąca). Niestety, tylko 31\% chorych, którzy przeżyli poniżej 4 miesięcy, było sklasyfikowanych w grupie o złym rokowaniu. W opinii Tabouret i wsp. zastosowanie dwóch czynników prognostycznych jest niewystarczające dla zdeterminowania rokowania u chorych z BMBC.

Oceniając PS opracowany przez Niwińską i Murawską, Tabouret i wsp. podkreślają jego wartość, szczególnie w wyodrębnieniu grupy chorych z bardzo złym rokowaniem (klasa III - MOS = 2,4 miesiąca). Zwracają jednak uwagę na - ich zdaniem - zbyt dominującą rolę KPS w tym PS: w klasie I prognostycznej, o najlepszym rokowaniu, wymagany KPS wynosił 100 (6\% chorych); KPS $\leq 60$ kwalifikował chorego do grupy III ( $27 \%$ chorych). Ponad 2/3 chorych kwalifikowało się więc do klasy Il, o bardzo różnych cechach prognostycznych.

Badania Parka i wsp. obejmowały populację chorych, na której nie stosowano w ogóle leczenia anty-HER2, co spowodowało, że cecha nadekspresji HER-2 związana była ze złym rokowaniem, i chore klasy I miały gorsze MOS aniżeli klasy II.

Analizując dwa pozostałe porównywane PS, Tabouret i wsp. stwierdzili, że PS opracowany przez Sperduto i wsp. miał PPV (positive predictive values) wynoszący 69\%, a opracowany przez Niedera i wsp. - 71\%. PPV był definiowany jako proporcja chorych z OS poniżej 3,5 miesiąca w najgorzej rokującej grupie i proporcja chorych z OS powyżej 14 miesięcy (mediana badanej grupy) w najlepiej rokującej grupie. Konkludując, autorzy pracy uznali, że w grupie chorych z BMBC, PS opracowany przez Niedera i wsp. prezentuje najlepszą wartość predykcyjną spośród badanych przez nich PS.

\section{Trudności i ograniczenia w stosowaniu PS u chorych na BMBC}

Pomimo niewątpliwych zalet PS istnieją pewne trudności i ograniczenia w ich stosowaniu u chorych z BMBC $[59,66,67,69,78]$.

Należą do nich:

1. Jak wskazują dane w tabelach II i III, tylko część PS uwzględnia szczególne cechy biologiczne i terapeutyczne BMBC, np. leczenie transtuzumabem chorych na BC z nadekspresją HER-2.

2. Charakterystyczną cechą niektórych PS jest brak jednorodności dystrybucji chorych pomiędzy różnymi katego- riami prognostycznymi. PS, które np. identyfikują bardzo małą liczebnie grupę chorych z doskonałą prognozą, mają ograniczony wpływ na decyzje terapeutyczne, gdyż jest to sytuacja rzadko spotykana w praktyce klinicznej.

3. Wiele czynników wchodzących w skład PS jest trudnych do obiektywnej oceny, np. omawiany już uprzednio stan procesu nowotworowego poza mózgiem, którego prognostyczne znaczenie istotnie zależy od lokalizacji tych przerzutów. Inną wagę ma pojedynczy przerzut do kości, a inną liczne przerzuty do narządów miąższowych. Różnica ta nie jest uwzględniana w większości PS.

4. Wiele PS jest krytykowanych z różnych powodów. Najbardziej znany RPA-RTOG został opracowany dla chorych poddanych WBRT, a np. SIR i BSBM - dla chorych leczonych SRS. Wiele PS nie uwzględnia liczby BM, czynnika, który w innych PS ma istotne znaczenie prognostyczne i wpływ na wybór metody leczenia. Rotterdam zalicza do czynników prognostycznych skuteczność indukcyjnej kortykosterydoterapii, co nie jest łatwe do obiektywnej oceny. Cztery PS dla BMBC nie uwzględniają obecności i rozległości przerzutów poza mózgiem (Park i wsp., Claude i wsp., Spertudo i wsp., Le Scodan i wsp.) [64, $68,70,76]$.

\section{Podsumowanie}

Podstawowymi czynnikami prognostycznymi u chorych na raka piersi z przerzutami do mózgu są: stan sprawności chorych (najczęściej określany przy użyciu skali Karnofsky'ego) oraz stan procesu nowotworowego poza mózgiem w momencie ujawnienia się tych przerzutów. Podnoszone przez część autorów niezależne, prognostyczne znaczenie wieku chorej oraz podtypu molekularnego raka piersi są przedmiotem trwającej dyskusji. Zastosowanie indeksów prognostycznych jest niewątpliwie postępem w ogólnie przyjętym leczeniu chorych z BMBC, jednak w praktyce klinicznej winny być one stosowane $z$ rozwagą.

\section{Konflikt interesu: nie zgłoszono}

Dr hab. med. Beata Sas-Korczyńska, prof. nadzw.

Oddział Nowotworów Piersi i Klatki Piersiowej, Klinika Onkologii Centrum Onkologii — Instytut im. Marii Skłodowskiej-Curie Oddział w Krakowie ul. Garncarska 11, 31-112 Kraków e-mail:z5korczy@cyf-kr.edu.pl

Otrzymano: 16 września 2014 r. Przyjęto do druku: 14 października 2014 r.

\section{Piśmiennictwo}

1. Gachet J, Giroux J, Girre V i wsp. Métastases cérébrales dans les cancers du sein. Épidémiologie et histoire naturelle. Expérience de I'Institut Curie à travers deux études: les patientes HER2- de moins de 65 ans et les patientes de plus de 65 ans. Bull Cancer 2011; 98: 357-369. 
2. Dayan A, Koca D, Akman Ti wsp. The factors that have an impact on the development of brain metastasis in the patients with breast cancer. J Cancer Res Ther 2012; 8: 542-548.

3. Kwon H, Oh SY, Kim SH i wsp. Clinical outcomes and breast cancer subtypes in patients with brain metastases. Onkologie 2010; 33: 146-152.

4. Arslan UY, Oksuzoglu B, Aksoy Si wsp. Breast cancer subtypes and outcomes of central nervous system metastases. Breast 2011; 20: 562-567.

5. Braccini AL, Azria D, Thezenas S i wsp. Prognostic factors of brain metastases from breast cancer: impact of targeted therapies. Breast 2013; 22: 993-998.

6. Nayak L, Lee EQ, Wen PY. Epidemiology of brain metastases. Curr Oncol Rep 2012; 14: 48-54.

7. Tallet A. Métastases cérébrales de cancer du sein. Cancer Radiother 2013; 17: 708-714.

8. Wilczura P, Senkus-Konefka E, Jassem J. Polskie i międzynarodowe zalecenia dotyczące leczenia raka piersi. Nowotwory J Oncol 2013; 63: 58-65.

9. Niwińska A, Rudnicka H, Krajewski R i wsp. Leczenie neurochirurgiczne i napromienianie przerzutów do mózgu u chorych na raka piersi - analiza przeżyć i czynników prognostycznych. Nowotwory J Oncol 2007; 57: 140-145.

10. Niwińska A, Tacikowska M, Murawska M. The effect of early detection of occult brain metastases in HER2-positive breast cancer patients on survival and cause of death. Int J Radiat Oncol Biol Phys 2010; 77: 1134-1139.

11. Graesslin O, Abdulkarim BS, Coutant C i wsp. Nomogram to predict subsequent brain metastasis in patients with metastatic breast cancer. J Clin Oncol 2010; 28: 2032-2037.

12. Minisini AM, Moroso S, Gerratana L i wsp. Risk factors and survival outcomes in patients with brain metastases from breast cancer. Clin Exp Metastasis 2013; 30: 951-956.

13. Sperduto PW, Kased N, Roberge D i wsp. The effect of tumor subtype on the time from primary diagnosis to development of brain metastases and survival in patients with breast cancer. J Neurooncol 2013; 112: 467-472.

14. Niwińska A, Murawska M, Pogoda K. Breast cancer brain metastases: differences in survival depending on biological subtype, RPA RTOG prognostic class and systemic treatment after whole-brain radiotherapy (WBRT). Ann Oncol 2010; 21: 942-948.

15. Aoyama $\mathrm{H}$. Radiation therapy for brain metastases in breast cancer patients. Breast Cancer 2011; 18: 244-251.

16. Dutertre $G$, Pouit $B$. Les métastases cérébrales des cancers du sein: qui, quand, et comment les opérer? Bull Cancer 2011; 98; 433-444.

17. Soffietti R, Trevisan E, Ruda R. Targeted therapy in brain metastasis. Curr Opin Oncol 2012; 24: 679-686.

18. Renfrow JJ, Lesser GJ. Molecular subtyping of brain metastases and implications for therapy. Curr Treat Options Oncol 2013; 14: 514-527.

19. Niwińska A, Murawska M, Pogoda K. Breast cancer subtypes and response to systemic treatment after whole-brain radiotherapy in patients with brain metastases. Cancer 2010; 116: 4238-4247.

20. Levitt MR, Levitt R, Silbergeld DL. Controversies in the management of brain metastases. Surg Neurol Int 2013; 4: (Suppl. 4) S231-235.

21. Niwińska A, Pogoda K, Murawska Mi wsp. Factors influencing survival in patients with breast cancer and single or solitary brain metastasis. Eur J Surg Oncol 2011; 37: 635-642.

22. Kaplan MA, Isikdogan A, Koca D i wsp. Clinical outcomes in patients who received lapatinib plus capecitabine combination therapy for HER2-positive breast cancer with brain metastasis and a comparison of survival with those who received trastuzumab-based therapy: a study by the Anatolian Society of Medical Oncology. Breast Cancer 2013 doi 10.1007/s 12282-013-0441-y.

23. Bachelot T, Le Rhun E, Labidi-Gally I i wsp. Traitements systémiques des métastases cérébrales des cancers du sein: chimiothérapies cytotoxiques et thérapies ciblées. Bull Cancer 2013; 100: 7-14.

24. Matsunaga S, Shuto T, Kawahara N i wsp. Gamma Knife surgery for metastatic brain tumors from primary breast cancer: treatment indication based on number of tumors and breast cancer phenotype. J Neurosurg 2010; 113 Suppl. : 65-72.

25. Kondziolka D, Kano H, Harrison GL i wsp. Stereotactic radiosurgery as primary and salvage treatment for brain metastases from breast cancer. J Neurosurg 2011; 114: 792-800.

26. Windsor AA, Koh ES, Allen S i wsp. Poor outcomes after whole brain radiotherapy in patients with brain metastases: results from an international multicentre cohort study. Clin Oncol 2013; 25: 674-680.

27. Boogerd W, Vos VW, Hart AA i wsp. Brain metastases in breast cancer; natural history, prognostic factors and outcome. J Neurooncol 1993; 15: $165-174$.
28. Berghoff A, Bago-Horvath Z, De Vries C i wsp. Brain metastases free survival differs between breast cancer subtypes. Br J Cancer 2012; 106: 440-446.

29. Kim HJ, Im SA, Keam B i wsp. Clinical outcome of central nervous system metastases from breast cancer: differences in survival depending on systemic treatment. J Neurooncol 2012; 106: 303-313.

30. Gaspar L, Scott C, Rotman M i wsp. Recursive partitioning analysis (RPA) of prognostic factors in three Radiation Therapy Oncology Group (RTOG) brain metastases trials. Int J Radiat Oncol Biol Phys 1997; 37: 745-751.

31. Evans AJ, James JJ, Cornford EJ i wsp. Brain metastases from breast cancer: identification of a high-risk group. Clin Oncol 2004; 16:345-349.

32. Lin NU, Winer EP. Brain metastases: the HER2 paradigm. Clin Cancer Res 2007; 13: 1648-1655

33. Slimane K, Andre F, Delaloge S i wsp. Risk factors for brain relapse in patients with metastatic breast cancer. Ann Oncol 2004; 15: 1640-1644.

34. Lin NU, Claus E, Sohl J i wsp. Sites of distant recurrence and clinical outcomes in patients with metastatic triple-negative breast cancer: high incidence of central nervous system metastases. Cancer 2008; 113: 2638-2645.

35. Albiges L, André F, Balleyguier C i wsp. Spectrum of breast cancer metastasis in BRCA1 mutation carriers: highly increased incidence of brain metastases. Ann Oncol 2005; 16: 1846-1847.

36. Weltman E, Salvajoli JV, Brandt RA i wsp. Radiosurgery for brain metastases: a score index for predicting prognosis. Int J Radiat Oncol Biol Phys 2000; 46: 1155-1161.

37. Le Scodan R, Massard C, Mouret-Fourme E i wsp. Brain metastases from breast carcinoma: validation of the radiation therapy oncology group recursive partitioning analysis classification and proposition of a new prognostic score. Int J Radiat Oncol Biol Phys 2007; 69: 839-845.

38. Gerdan L, Segedin B, Nagy i wsp. The number of involved extracranial organs: a new predictor of survival in breast cancer patients with brain metastasis. Clin Neurol Neurosurg 2013; 115: 2108-2110.

39. Rades D, Lohynska R, Veninga T i wsp. Evaluation of 2 whole-brain radiotherapy schedules and prognostic factors for brain metastases in breast cancer patients. Cancer 2007; 110: 2587-2592.

40. Xu Z, Marko NF, Angelov L i wsp. Impact of preexisting tumor necrosis on the efficacy of stereotactic radiosurgery in the treatment of brain metastases in women with breast cancer. Cancer 2012; 118: 1323-1333.

41. Nam BH, Kim SY, Han HS i wsp. Breast cancer subtypes and survival in patients with brain metastases. Breast Cancer Res 2008; 10: R20.

42. Eichler AF, Kuter I, Ryan P i wsp. Survival in patients with brain metastases from breast cancer: the importance of HER-2 status. Cancer 2008; 112: 2359-2367.

43. Liu MT, Hsieh CY, Wang AY i wsp. Prognostic factors affecting the outcome of brain metastases from breast cancer. Support Care Cancer 2006; 14: 936-942.

44. Viani GA, Castilho MS, Salvajoli JV i wsp. Whole brain radiotherapy for brain metastases from breast cancer: estimation of survival using two stratification systems. BMC Cancer 2007; 7: 53

45. Golden DW, Lamborn KR, McDermott MW i wsp. Prognostic factors and grading systems for overall survival in patients treated with radiosurgery for brain metastases: variation by primary site. J Neurosurg 2008; 109: 77-86.

46. Lederman $G$, Wronski $M$, Fine $M$. Fractionated radiosurgery for brain metastases in 43 patients with breast carcinoma. Breast Cancer Res Treat 2001; 65: 145-154.

47. Muacevic A, Kreth FW, Tonn JC, Wowra B. Stereotactic radiosurgery for multiple brain metastases from breast carcinoma. Cancer 2004; 100: 1705-1711.

48. Kased N, Binder DK, McDermott MW i wsp. Gamma Knife radiosurgery for brain metastases from primary breast cancer. Int J Radiat Oncol Biol Phys 2009; 75: 1132-1140.

49. Lower EE, Drosick DR, Blau R i wsp. Increased rate of brain metastasis with trastuzumab therapy not associated with impaired survival. Clin Breast Cancer 2003; 4: 114-119.

50. Kirsch DG, Ledezma CJ, Mathews CS i wsp. Survival after brain metastases from breast cancer in the trastuzumab era. J Clin Oncol 2005; 23: 2114-2116.

51. Bartsch R, Rottenfusser A, Wenzel Ci wsp.Trastuzumab prolongs overall survival in patients with brain metastases from Her2 positive breast cancer. J Neurooncol 2007; 85: 311-317.

52. Wolstenholme V, Hawkins M, Ashley S i wsp. HER2 significance and treatment outcomes after radiotherapy for brain metastases in breast cancer patients. Breast 2008; 17: 661-665. 
53. Vern-Gross TZ, Lawrence JA, Case LD i wsp. Breast cancer subtype affects patterns of failure of brain metastases after treatment with stereotactic radiosurgery. J Neurooncol 2012; 110: 381-388.

54. Sperduto PW, Kased N, Roberge Diwsp. Effect of tumor subtype on survival and the graded prognostic assessment for patients with breast cancer and brain metastases. Int J Radiat Oncol Biol Phys 2012; 82: 2111-2117.

55. Kirova YM, Chargari C, Mazeron J-J. Métastases cérébrales multiples d'un cancer du sein et leur prise en charge en radiothérapie: quelle est I'attitude thérapeutique la mieux adaptée? Bull Cancer 2011; 98:409-415.

56. Lagerwaard FJ, Levendag PC, Nowak PJ i wsp. Identification of prognostic factors in patients with brain metastases: a review of 1292 patients. Int J Radiat Oncol Biol Phys 1999; 43: 795-803.

57. Antoni $D$, Noël $G$. Adaptation de la radiothérapie des métastases cérébrales selon laclassification GPA (Graded Prognostic Assessment). Cancer/Radiother 2013; 17: 424-427.

58. Sperduto PW, Kased N, Roberge D i wsp. Summary report on the graded prognostic assessment: an accurate and facile diagnosis-specific tool to estimate survival for patients with brain metastases. $J$ Clin Oncol 2012; 30: 419-425.

59. Le Scodan R, Massard C, Noël G. Facteurs pronostiques des métastases cérébrales Bull Cancer 2013; 100: 45-50.

60. Niwińska A, Murawska M. New breast cancer recursive partitioning analysis prognostic index in patients with newly diagnosed brain metastases. Int J Radiat Oncol Biol Phys 2012; 82: 2065-2071.

61. Le Scodan R, Massard C, Jouanneau L i wsp. Brain metastases from breast cancer: proposition of new prognostic score including molecular subtypes and treatment. J Neurooncol 2012; 106: 169-176.

62. Sperduto PW, Chao ST, Sneed PK i wsp. Diagnosis-specific prognostic factors, indexes, and treatment outcomes for patients with newly diagnosed brain metastases: a multi-institutional analysis of 4,259 patients. Int J Radiat Oncol Biol Phys 2010; 77: 655-661.

63. Nieder C, Marienhagen K, Astner ST, Molls M. Prognostic scores in brain metastases from breast cancer. BMC Cancer 2009; 9: 105.

64. Park BB, Uhm JE, Cho EY i wsp. Prognostic factor analysis in patients with brain metastases from breast cancer: how can we improve the treatment outcomes? Cancer Chemother Pharmacol 2009; 63: 627-633.

65. Tabouret E, Metellus P, Gonçalves A i wsp. Assessment of prognostic scores in brain metastases from breast cancer. Neuro Oncol 2014; 16: 421-428.

66. Braccini AL, Azria D, Thezenas S i wsp. Comparative performances of prognostic indexes for breast cancer patients presenting with brain metastases. BMC Cancer 2013; 13: 70.
67. Nieder C, Dalhaug A. A new prognostic score derived from phase I study participants with advanced solid tumours is also valid in patients with brain metastasis. Anticancer Res 2010; 30: 977-979.

68. Claude L, Perol D, Ray-Coquard I i wsp. Lymphopenia: a new independent prognostic factor for survival in patients treated with whole brain radiotherapy for brain metastases from breast carcinoma. Radiother Oncol 2005; 76: 334-339.

69. Antoni D, Clavier JB, Pop M i wsp. An institutional retrospective analysis of 93 patients with brain metastases from breast cancer: treatment outcomes, diagnosis-specific prognostic factors. Int J Mol Sci 2012; 13: 16489-16499.

70. Sperduto PW, Berkey B, Gaspar LE i wsp. A new prognostic index and comparison to three other indices for patients with brain metastases: an analysis of 1,960 patients in the RTOG database. Int J Radiat Oncol Biol Phys 2008; 70: 510-514.

71. Rades D, Dunst J, Schild SE. A new scoring system to predicting the survival of patients treated with whole-brain radiotherapy for brain metastases. Strahlenther Onkol 2008; 184: 251-255.

72. Park YH, Park MJ, Ji SH i wsp. Trastuzumab treatment improves brain metastasis outcomes through control and durable prolongation of systemic extracranial disease in HER2-overexpressing breast cancer patients. Br J Cancer 2009; 100: 894-900.

73. Yan M, Lü HM, Liu ZZ i wsp. High risk factors of brain metastases in 295 patients with advanced breast cancer. Chin Med J 2013; 126: 1269-1275.

74. Xu Z, Marko NF, Chao ST i wsp. Relationship between HER2 status and prognosis in women with brain metastases from breast cancer. Int $J$ Radiat Oncol Biol Phys 2012; 82: e739-747.

75. Larsen PB, Kümler I, Nielsen DL.A systematic review of trastuzumab and lapatinib in the treatment of women with brain metastases from HER2-positive breast cancer. Cancer Treat Rev 2013; 39: 720-727.

76. Le Scodan R, Massard Ch, Jouanneau L i wsp. Métastases cérébrales des cancers du sein: intérêt et limites des scores pronostiques. Bull Cancer 2011; 98: 377-384.

77. Lorenzoni J, Devriendt D, Massager N i wsp. Radiosurgery for treatment of brain metastases: estimation of patient eligibility using three stratification systems. Int J Radiat Oncol Biol Phys 2004; 60: 218-224.

78. Jakubowicz J, Walasek T, Reinfuss M i wsp. Indeksy prognostyczne dla chorych na czerniaka z przerzutami do mózgu. Onkol Radiot 2014; 26-27: 11-16. 